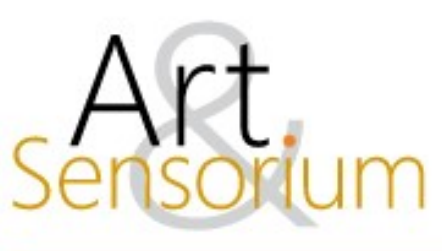

\title{
A “ODISSEIA" DE AI WEIWEI: FÓRMULAS ANTIGAS ENTRE O ÉPICO E O TRÁGICO NA ARTE CONTEMPORÂNEA \\ https://doi.org/10.33871/23580437.2021.8.1.103-117
}

\author{
Sandra Makowiecky ${ }^{1}$ \\ Luana Maribele Wedekin ${ }^{2}$
}

\begin{abstract}
Resumo: Na mostra "Raiz" (2018), de Ai Weiwei na Oca, São Paulo, o visitante podia contemplar um grande mural estampado em adesivo vinílico que cobria um elemento arquitetônico da edificação. Tratava-se da obra "Odisseia" (2017), cujo tema central é a crise contemporânea de refugiados. Consiste numa sequência de figuras, tratadas em preto e branco como silhuetas bidimensionais que lembram as antigas pinturas em cerâmica gregas, nas quais vemos cenas de guerra, ruínas, viagem, travessia marítima, campos de refugiados e manifestações. Para o argumento deste artigo, aproximamos Ai Weiwei de Aby Warburg. Podemos identificar nas silhuetas de "Odisseia" diversas fórmulas de pathos (pathosformeln): a agressão e a defesa; o gesto da proteção (anjo e criança); a ninfa canéfora; o herói morto e as formas de luto. Parece-nos pertinente, então, retornar à questão perseguida por Warburg durante sua vida sobre a restituição do antigo, dessa vez no contemporâneo. Como e por que essas formas/fórmulas antigas retornam? A pertinência do problema de Warburg toca uma concepção de história da arte que se debruça sobre as experiências da comoção humana. O ativismo de Weiwei é pensado à luz das categorias de épico e trágico como descritas por George Steiner acerca de Tolstói e Dostoiévski.
\end{abstract}

Palavras-chave: Ai Weiwei; Pathosformeln; Aby Warburg e arte contemporânea; Épico na arte contemporânea; Trágico na arte contemporânea.

\section{AI WEIWEI'S "ODYSSEY": ANCIENT FORMULAS BETWEEN THE EPIC AND THE TRAGIC IN CONTEMPORARY ART}

\begin{abstract}
In the exhibition "Raiz" (2018) by Ai Weiwei in São Paulo, the visitor could contemplate a large mural printed in vinyl sticker that covered an architectural element of the building. It was the work "Odyssey" (2017), whose central theme is the contemporary refugee crisis. It consists of a sequence of figures, treated in black and white as two-dimensional silhouettes that resemble ancient Greek ceramic paintings, in which we see scenes of war, ruins, travel, sea crossing, refugee camps and demonstrations. For the argument of this article, we approach Weiwei with Aby Warburg. We can identify in the silhouettes of "Odisseia" several formulas of pathos (pathosformeln): aggression and defense; the protection gesture (angel and child); the nymph; the dead hero and the forms of mourning. It seems pertinent, then, to return to the question pursued by Warburg throughout his life about the restitution of the antique, this time in the contemporary. How and why do these old formulas return? The relevance of Warburg's problem touches on a conception of art history that
\end{abstract}

\footnotetext{
${ }^{1}$ http://lattes.cnpq.br/7738155362538526. Professora titular da Universidade do Estado de Santa Catarina. Teoria e História da arte. Universidade do Estado de Santa Catarina - Centro de Artes Departamento de Artes Visuais. sandra.makowiecky@gmail.com

${ }^{2}$ http://lattes.cnpq.br/5239304823588475. Professora adjunta da Universidade do Estado de Santa Catarina. Teoria e História da arte. Centro de Artes Departamento de Artes Visuais.wedekinluana@gmail.com
} 
focuses on the experiences of human commotion. Weiwei's activism is thought in the light of the categories of epic and tragic as described by George Steiner about Tolstoy and Dostoevsky.

Key-words: Ai Weiwei; Pathosformeln; Aby Warburg and contemporary art; Epic in contemporary art; Tragic in contemporary art.

\section{LA "ODISEA" DE AI WEIWEI: FÓRMULAS ANTIGUAS ENTRE LO ÉPICO Y LO TRÁGICO EN EL ARTE CONTEMPORÁNEO}

Resumen: En la exposición "Raiz" (2018) de Ai Weiwei en Oca, São Paulo, el visitante pudo contemplar un gran mural impreso en vinilo adhesivo que cubría un elemento arquitectónico del edificio. Fue la obra "Odisea" (2017), cuyo tema central es la crisis de refugiados contemporánea. Consiste en una secuencia de figuras, tratadas en blanco y negro como siluetas bidimensionales que recuerdan las antiguas pinturas de cerámica griega, en las que vemos escenas de guerra, ruinas, viajes, travesías marítimas, campos de refugiados y manifestaciones. Para el argumento de este artículo, nos acercamos a Ai Weiwei con Aby Warburg. Podemos identificar en las siluetas de "Odisseia" varias fórmulas de pathos (pathosformeln): agresión y defensa; el gesto de protección (ángel y niño); la ninfa; el héroe muerto y las formas del duelo. Parece pertinente, entonces, volver a la pregunta que Warburg ha perseguido a lo largo de su vida sobre la restitución de lo antiguo, esta vez en lo contemporáneo. ¿Cómo y por qué regresan estas viejas formas / fórmulas? La relevancia del problema de Warburg toca una concepción de la historia del arte que se centra en las experiencias de la conmoción humana. El activismo de Weiwei se piensa a la luz de las categorías de épico y trágico descritas por George Steiner sobre Tolstoi y Dostoievski.

Palabras llave: Ai Weiwei; Pathosformeln; Aby Warburg y el arte contemporáneo; Épico en el arte contemporáneo; Trágico en el arte contemporáneo.

\section{Introdução}

Na mostra "Raiz" (2018), de Ai Weiwei na Oca, São Paulo, o visitante podia contemplar um grande mural estampado em adesivo vinílico que cobria paredes da edificação. Tratava-se da obra "Odisseia" (2017). Em sua pesquisa artística, Ai Weiwei frequentemente promove confrontações com a tradição, inúmeras vezes em ações de quebra ou reformulação/ressignificação da arte do passado; por exemplo, em sua conhecida performance Dropping a Han Dinasty Urn (1995), o artista larga ao chão uma urna cerimonial de dois mil anos da dinastia Han. O tema central de "Odisseia" é a crise contemporânea de refugiados, mas que muito perspicazmente o artista faz remeter também à Antiguidade. Consiste numa sequência de figuras, tratadas em preto e branco como silhuetas bidimensionais que lembram as antigas pinturas em cerâmica gregas, nas quais vemos cenas de guerra, ruínas, viagem, travessia marítima, campos de refugiados e manifestações.

Para o argumento deste artigo, aproximamos Ai Weiwei de Aby Warburg. Podemos identificar nas silhuetas de "Odisseia" diversas fórmulas de pathos (pathosformeln): a agressão e a defesa; o gesto da proteção (anjo e criança); a ninfa canéfora; o herói morto e as formas de luto. Parece-nos pertinente, então, retornar à questão perseguida por Warburg durante toda a vida sobre a restituição do antigo, dessa vez no contemporâneo. Como e por que essas formas/fórmulas antigas retornam? A pertinência do problema de Warburg toca uma concepção de história da arte que se debruça sobre as experiências da comoção humana. O ativismo de Ai Weiwei diferencia-se de muitos dos empobrecidos ativismos da agenda contemporânea para justamente tratar da transmissão dos estados da alma estudados por Warburg. 
Sobre o artista e sua biografia ${ }^{3}$

\author{
[...] como no mar padeceu sofrimentos inúmeros na alma, \\ para que a vida salvasse e de seus companheiros a volta. \\ Os companheiros, porém, não salvou, muito embora o \\ tentasse [...]. (HOMERO, 2011, p. 35).
}

Ai Weiwei é atualmente um dos artistas mais celebrados da cena global contemporânea, atuando como "artista, poeta, arquiteto, curador, especialista em artesanato chinês antigo, editor, urbanista, colecionador, blogueiro" (OBRIST, 2018, p. 11). Nascido em Pequim, em 1957, sua trajetória passa pela infância marcada pela experiência do exílio de seu pai, o poeta moderno Ai Quing, por acusação de anticomunismo pelo governo chinês, seguida de estudos de animação na Academia de Cinema de Pequim (1978); fundação do primeiro movimento artístico que se afasta das políticas estéticas do Partido Comunista (1979); mudança para os Estados Unidos, onde estudou e trabalhou, primeiramente na Filadélfia, depois Berkeley e, finalmente, Nova Iorque, totalizando 12 anos nesse país. Em razão do pai enfermo, retornou a Pequim em 1993, onde começou a colecionar artefatos chineses antigos, editar e publicar textos que promovem a vanguarda chinesa; em 1997, criou, em Pequim, o Arquivo e Armazém de Arte Chinesa, o primeiro espaço de arte contemporânea interdependente da China; em 1999, participou da Bienal de Veneza. Sua atuação diversifica-se ainda mais, com trabalhos também em arquitetura, dentre os quais, o mais notável é o Estádio Nacional de Pequim, construído para os Jogos Olímpicos de Verão em 2008, realizado em colaboração com os arquitetos Herzog e de Meuron.

Em 2005, criou um blog, cujos escritos abrangem muitos temas, "comentários sociais, críticas da política governamental e seus pensamentos sobre arte e arquitetura" (DANTAS, 2018, p.185). O blog revela preocupações sociais que levam o curador Hans Ulrich Obrist (2018) a qualificar sua atuação de "escultura social", termo tomado de empréstimo do artista alemão Joseph Beuys (19211986). Cunhado na década de 1970, o conceito "unia as ideias idealistas de Joseph Beuys de uma sociedade utópica com sua prática estética. Ele acreditava que a vida é uma escultura social que todos ajudam a moldar" (SOCIAL SCULPTURE, 2020). Um exemplo claro desse tipo de atuação do artista chinês diz respeito à mobilização coletiva criada por Weiwei através de seu blog para levantar dados sobre milhares de estudantes chineses mortos no terremoto na província de Sichuan, em 2008. O governo chinês não tratou a tragédia com transparência, e a atuação do artista lançou luz à má qualidade das construções das escolas em Sichuan. Nessa importante ação em defesa dos direitos civis, o artista catalisou informações (nomes e datas de nascimento) de 5.196 estudantes mortos (DANTAS, 2018).

Esse episódio rendeu-lhe o encerramento do blog e uma detenção policial com agressão que lhe causou uma hemorragia cerebral. O governo iniciou uma perseguição sistemática ao artista - num movimento de acirramento da repressão a dissidentes em geral - com consequências diversas: demolição de seu ateliê em janeiro de 2011 (com menos de 24 horas de aviso prévio); prisão domiciliar; prisão em lugar secreto por 81 dias (em 2011); confisco de seu passaporte e proibição de viajar ao exterior por cinco anos; problemas fiscais (multas e impostos atrasados no montante de quase 900 mil reais). Uma campanha para arrecadar fundos em benefício do artista mobilizou 30.000 pessoas. Mesmo à distância, participou de inúmeras exposições, como a Bienal de Veneza de 2013. Em 2015, a Anistia Internacional concedeu a Weiwei o prêmio Embaixador da Consciência, por seu trabalho em defesa dos direitos humanos. Nesse mesmo ano, ao ser restituído seu passaporte, mudou-se para Berlim, onde vive e trabalha até hoje, também como docente da Universidade de Artes de Berlim.

\footnotetext{
${ }^{3}$ Baseada na cronologia do catálogo: "Raiz Weiwei” (2018).
} 
A partir de 2016, o artista começou a se interessar pela questão dos refugiados, viajando para a ilha de Lesbos, na Grécia, uma das portas de entrada de barcos de refugiados e onde se encontra o campo destes em Moria. Essa visita rendeu a decisão de produzir o documentário "Fluxo Humano" (Human Flow) ${ }^{4}$, "experimento visual do maior deslocamento humano desde a Segunda Guerra Mundial" (DANTAS, 2018, p. 189). O artista e sua equipe visitaram mais de quarenta campos de refugiados em 23 países, entrevistando mais de 600 deles, voluntários e contrabandistas. Sobre o tema, também produziu diversas instalações: Passagem Segura (Safe Passage); Lava-Roupas automática (Laundromat); Lei da Viagem (também em exposição na Oca em 2018). Uma frase abre o site do documentário Human Flow: "Quando não há nenhum lugar para ir, nenhum lugar é o lar" (When there is nowhere to go, nowhere is home) ${ }^{5}$.

\section{A obra Odisseia e arte contemporânea como refúgio das fórmulas antigas}

O consistente debruçar-se de Ai Weiwei sobre a questão dos refugiados é o contexto da obra "Odisseia" (2017), grande mural estampado em vinil adesivo que estava exposto na mostra individual do artista: "Raiz" (2018), ocorrida na Oca, em São Paulo (Figura 1). Compreende uma sequência de figuras, tratadas em preto e branco como silhuetas bidimensionais que lembram as antigas pinturas em cerâmica gregas, nas quais vemos cenas de guerra, ruínas, viagem, travessia marítima, campos de refugiados e manifestações.
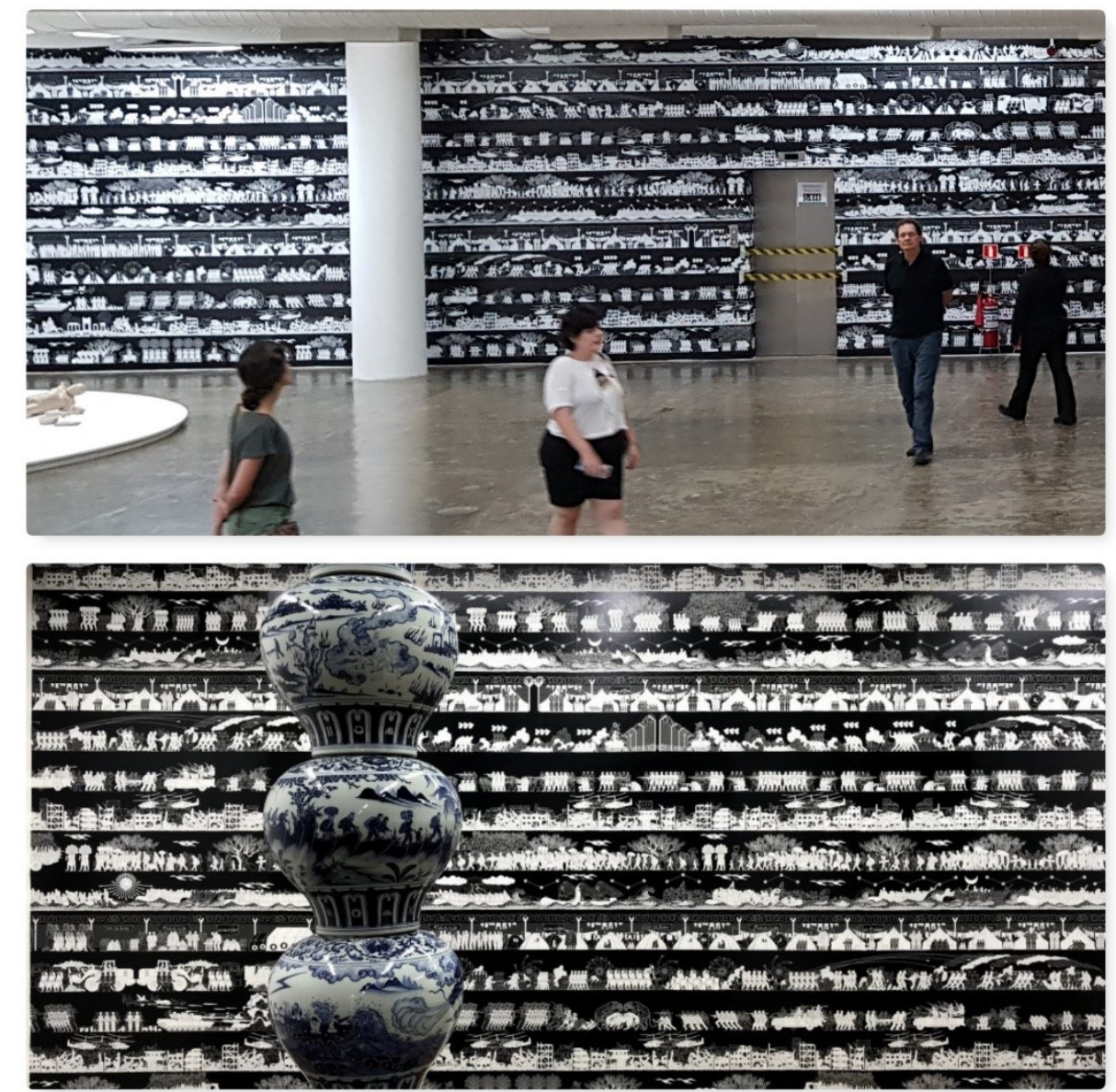

Figura 1 - Ai Weiwei, Odisseia, 2017. Vinil adesivo. Oca, São Paulo.

Fonte: Arquivo da autora (acima) e http://giovanni.minharadio.fm/ (abaixo).

\footnotetext{
${ }^{4} \mathrm{https}: / / \mathrm{www} \cdot$ youtube.com/watch? $\mathrm{v}=$ jO9DqVztLQ

${ }^{5}$ https://www.humanflow.com/
} 
O painel é resultado dos registros que a equipe de Weiwei realizou ao visitar os campos de refugiados para o documentário Human Flow. Vizinho a esse mural, estava uma outra instalação com milhares de fotografias tiradas durante a realização desse documentário. Mas no painel de vinil adesivo, as imagens foram tratadas, simplificadas até assumirem caráter de silhueta, enfatizando os elementos da linguagem visual da linha e da superfície. Aqui também podemos identificar a serialidade, um elemento constante na obra de Weiwei ${ }^{6}$. As imagens são organizadas em camadas de faixas horizontais dando uma sensação de continuidade às cenas ${ }^{7}$.

Um argumento central deste artigo diz respeito à relação da obra de Ai Weiwei com a tradição. O artista assume atitudes muito diversas e aparentemente contraditórias em suas obras: ele pode se utilizar de formas muito tradicionais, saberes de ofício da cultura tradicional chinesa, como a escultura Taifeng (2015), feita com bambu e papel de seda, utilizando técnicas tradicionais de fazer pipas e tomando como tema o texto clássico Shanhaijing, que data de antes do século IV a. C. Ou o "Mapa da China" (2017), escultura feita com madeira recuperada dos templos destruídos da Dinastia Qing (1644-1911), utilizando técnicas de marcenaria tradicionais, sem uso de pregos ou cola. Mas, também, pode quebrar deliberadamente - performaticamente - uma urna cerimonial de 2.000 anos da dinastia Han em Dropping a Han Dinasty Urn (1995) ou em seus vasos de porcelana (2010), nos quais tomou vasos da mesma dinastia Han e os cobriu com tinta industrial.

No painel "Odisseia" (2017), Weiwei tensiona a tradição ocidental. E, diferentemente do provocativo gesto de mostrar o dedo do meio para monumentos como a catedral de Milão ou a Torre Eiffel, de Paris, nas imagens dessa obra específica, fica claro que o artista não pretende apenas rejeitar o passado. Olhando as imagens individualmente, umas características chamam a atenção: algumas parecem retiradas diretamente das fotos captadas no intenso trabalho de campo para a realização de Human Flow, mas, dentre elas, o artista inseriu figuras reconhecíveis da tradição artística ocidental.

Podemos identificar uma figura em contorno que tanto pode tratar-se de Apolo tocando sua lira, coroado de louros, quanto Orfeu (Figura 2). A figura aparece duplicada, alternando figura preta em contorno branco ou figura branca em contorno preto. Podemos pensar num bardo que conta os horrores da guerra e da fuga (como Homero narrando as desventuras de Ulisses e seus companheiros), ou Orfeu que visita os mundos infernais - cujos limites estão demarcados por telas de arame e concertina - e retorna para contar. O trabalho de Weiwei com refugiados de diversos lugares assume papel de testemunho ${ }^{8}$.

\footnotetext{
${ }^{6}$ Obrist (2018) afirma a influência de Andy Warhol na obra de Weiwei. O artifício da serialidade pode ser verificado nessa identificação, mas também pode ser referência à cultura chinesa, e podemos falar de serialidade desde o impressionante exército de terracota do imperador Qin Shi Huang, datado de c. 210-209 a.C. até a atual vocação industrial praticamente imbatível globalmente da economia chinesa.

${ }^{7}$ Uma bela animação com as imagens do painel coloca as cenas em movimento: https://vimeo.com/470932544

${ }^{8}$ Aqui podemos remeter à reflexão sobre o testemunho nos termos levantados por Georges Didi-Huberman (2020) e Giorgio Agamben (2008) acerca do Holocausto.
} 


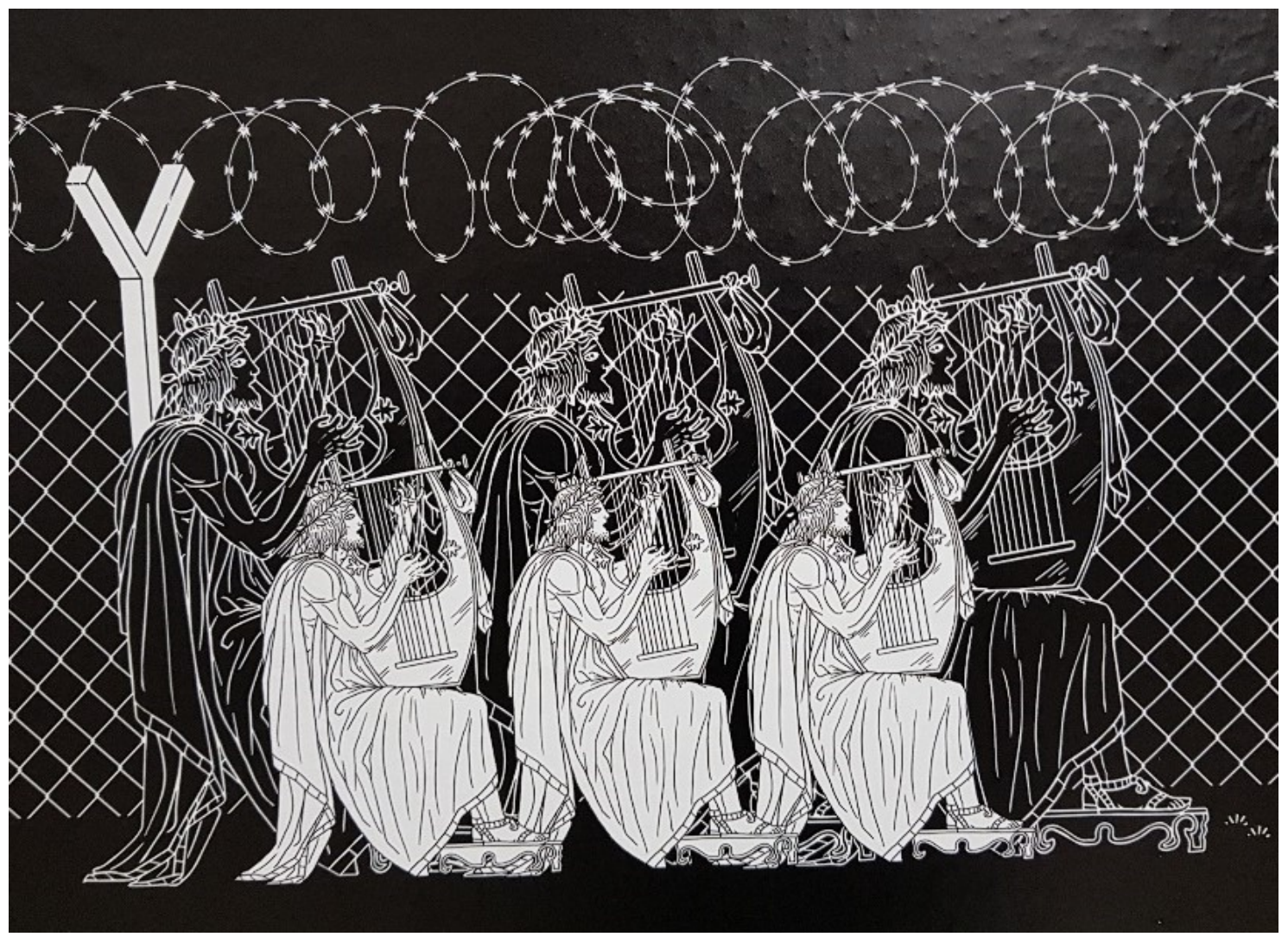

Figura 2 - Ai Weiwei, Odisseia (detalhe), 2017. Vinil adesivo. Oca, São Paulo.

Fonte: Arquivo da autora.

O universo dos refugiados e seus campos é aquele dos limiares. Tempo suspenso entre memórias e a expectativa de futuro, uma vida deixada para trás em busca de paz e dignidade. Os refugiados de Ai Weiwei também parecem vir de outros tempos, e contornos de guerreiros espartanos em batalha são vislumbrados (Figura 3). Numa sequência que claramente denota movimento, guerreiros à esquerda investem contra soldados que caem lentamente à direita. A escala das figuras também parece revelar forças monumentais que reverberam em gestos de agressão, de defesa e de rendição. A familiaridade dos gestos faz pensar imediatamente no conceito de pathosformeln, de Aby Warburg. 


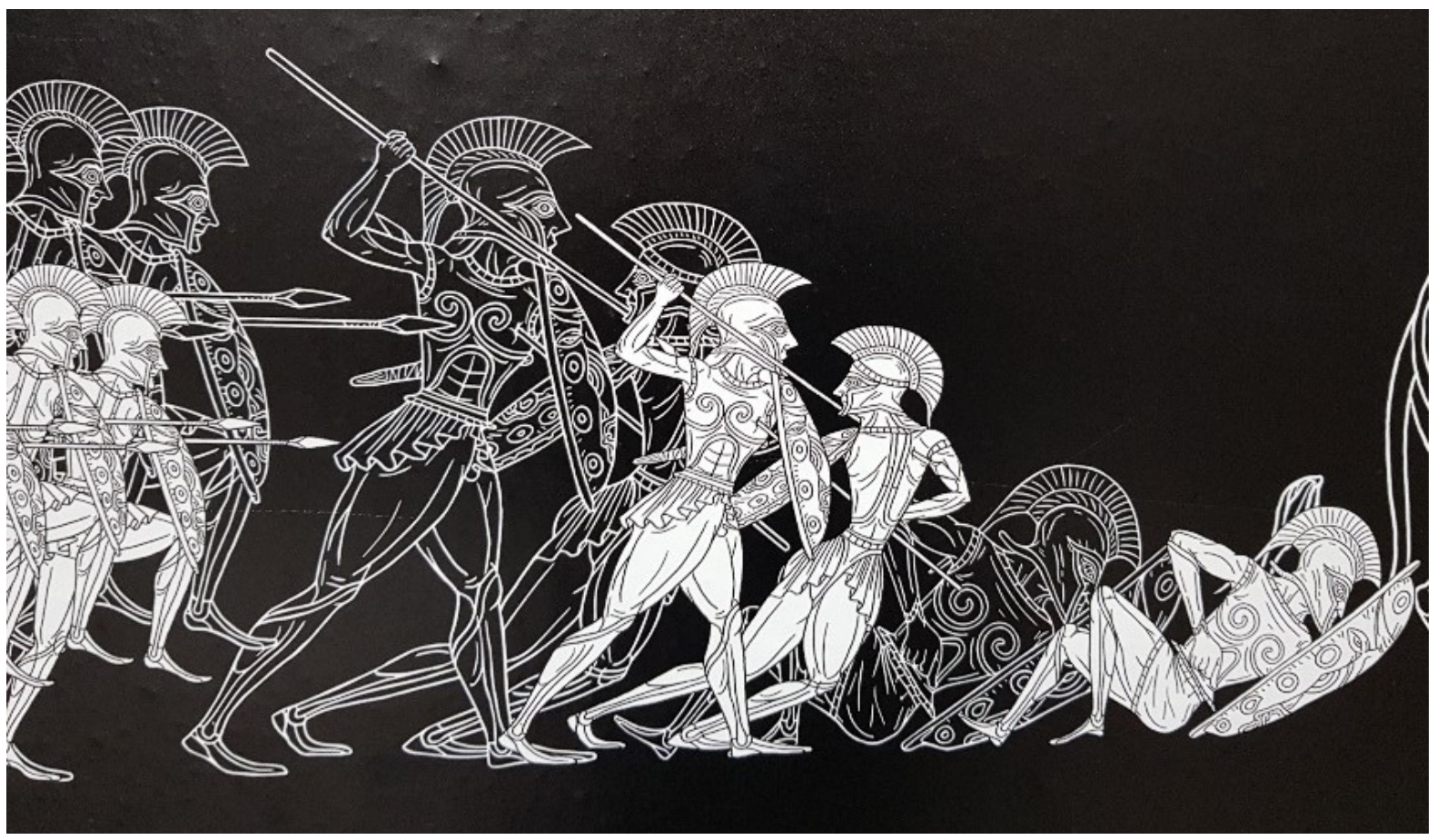

Figura 3 - Ai Weiwei, Odisseia (detalhe), 2017. Vinil adesivo. Oca, São Paulo Fonte: Arquivo da autora.

O conceito de "fórmula de pathos" aparece pela primeira vez em 1905 no escrito de Warburg (2013) sobre Albrecht Dürer. Aproximando a gravura "A morte de Orfeu" (1484), de Dürer (Figura 4), com uma gravura de mesmo tema do século XV atualmente atribuída a um anônimo, Warburg demonstra que "o gesto defensivo de Orfeu era uma fiel adoção de um motivo que retornava à Antiguidade" (HURTTIG, 2013, p. 17).

Comparando, ainda, o mesmo gesto que aparece também numa ilustração das Metamorfoses, de Ovídio, datada de 1494, o historiador conclui:

Ressoa nessa imagem a voz autenticamente antiga, tão familiar ao Renascimento: a morte de Orfeu não representava apenas um motivo artístico de interesse meramente formal, antes era uma experiência arraigada no obscuro mistério da saga dionisíaca, verdadeiramente revivida de modo passional e empático no espírito e segundo as palavras do remoto passado pagão [...] (WARBURG, 2013, p. 436).

Estudos contemporâneos mais ou menos fielmente inspirados em Aby Warburg têm proliferado enormemente. $\mathrm{O}$ interesse em sua obra reconhece a validade e a atualidade de suas interrogações: por que e como o antigo retorna e persiste? A sobrevida das fórmulas de pathos toma corpo no painel de Ai Weiwei, a "Odisseia" dos refugiados contemporâneos é a odisseia das imagens viajantes de outros tempos e lugares. Referem-se a "experiências de comoção humana" (WARBURG, 2018, p. 228). São o que Didi-Huberman chamou de "emoções figuradas, gestos emotivos" (2016, p. 35).

O gesto de agressão e de defesa evocado pelos guerreiros espartanos em combate e no ataque das mênades a Orfeu aparece no confronto entre refugiados e polícia (Figura 4). 

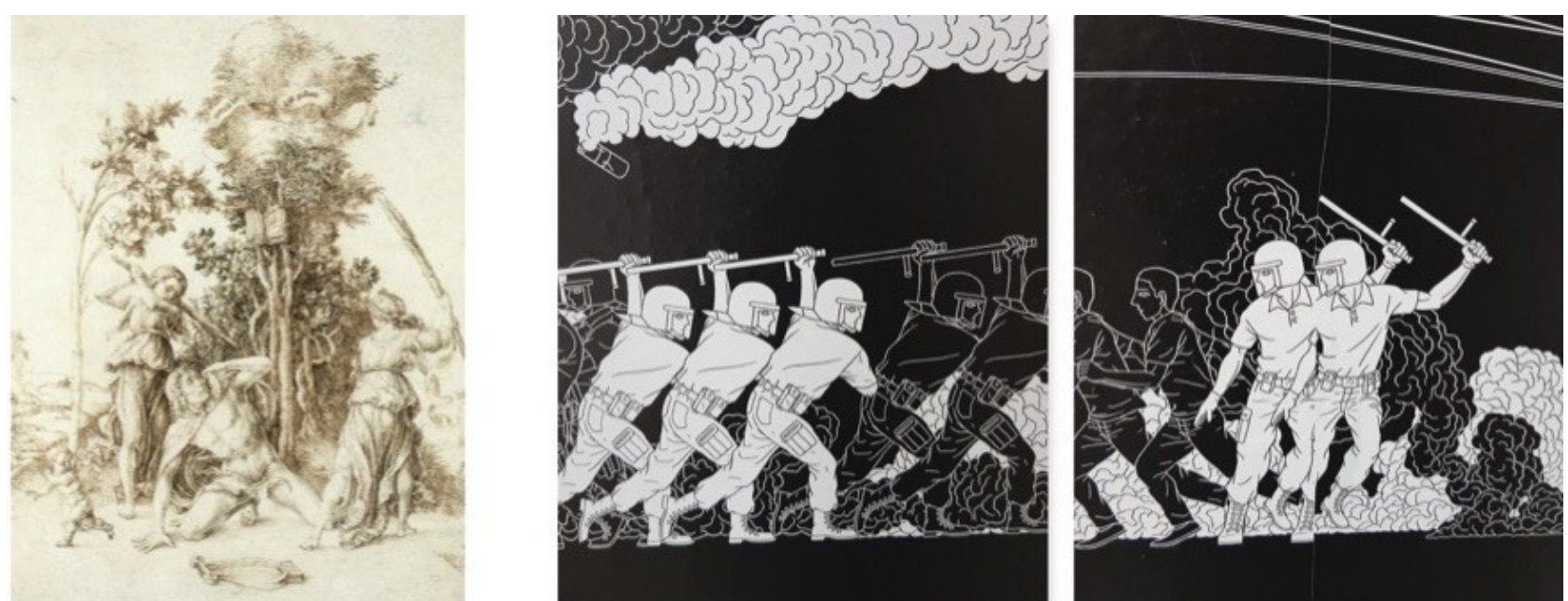

Figura 4 - À esq. Albrecht Dürer, A morte de Orfeu, 1494. Bico de pena sobre papel, 28.9 x $22.5 \mathrm{~cm}$, Kunsthalle. Fonte: http://warburg.chaa-unicamp.com.br/img/obras/576_original.jpg

À dir. Ai Weiwei, Odisseia (detalhes), 2017. Vinil adesivo. Oca, São Paulo. Fonte: Arquivo da autora.

O painel incorpora igualmente fórmulas de páthos não inventariadas por Warburg, mas por Georges Didi-Huberman, em sua recente exposição itinerante Levantes (2018). Ele abre a introdução do catálogo mencionando os refugiados em Idomeni, norte da Grécia, e menciona a presença de Ai Weiwei no campo de refugiados. Apesar de afirmar que "a arte não só tem uma história, mas frequentemente se apresenta como 'o próprio olho' da história” (DIDI-HUBERMAN, 2017, p. 14), o historiador da arte e filósofo francês expressa uma visão crítica da presença do artista naquele contexto:

Infelizmente, porém, não é a presença de Ai Weiwei em Idomeni, com seu piano branco e sua equipe de fotógrafos especializados ${ }^{9}$ que vai ajudar quem quer que seja ou o que quer que seja (os refugiados já se mostraram alheios à 'performance', têm a cabeça em outro lugar, esperam outra coisa) diante dessa questão abissal. Vejo aquele piano branco, surreal no meio do terreno baldio do campo, como símbolo derrisório das nossas boas consciências artísticas: branco como as paredes da galeria de arte, ele apenas evoca o contraste pelo qual, de coração aflito, vemos, tanto em Idomeni quanto em outros lugares, os tempos sombrios pesarem sobre nossas vidas contemporâneas. (DIDI-HUBERMAN, 2017, p. 14).

No ciclo vertiginoso das imagens do painel "Odisseia", se os policiais encarnam o gesto de agressão na tentativa de reprimir o avanço dos refugiados, observamos igualmente sua reação, defendendo-se com as armas que têm (Figura 5). Weiwei percebeu claramente a força do gesto de sublevação. (Impossível saber se sensibilizado já por imagens da primeira exposição sobre o tema de DidiHuberman no Jeu-de-Paume, em Paris, em 2016).

\footnotetext{
${ }^{9}$ Jornais de diversos países europeus noticiaram o evento e, se a estratégia de Ai Weiwei era ganhar as mídias, ele parece ter sido bem sucedido. Ver: https://www.dw.com/en/piano-in-the-mud-of-idomeni-shames-eu-over-refugeehaggling/a-19113544.
} 


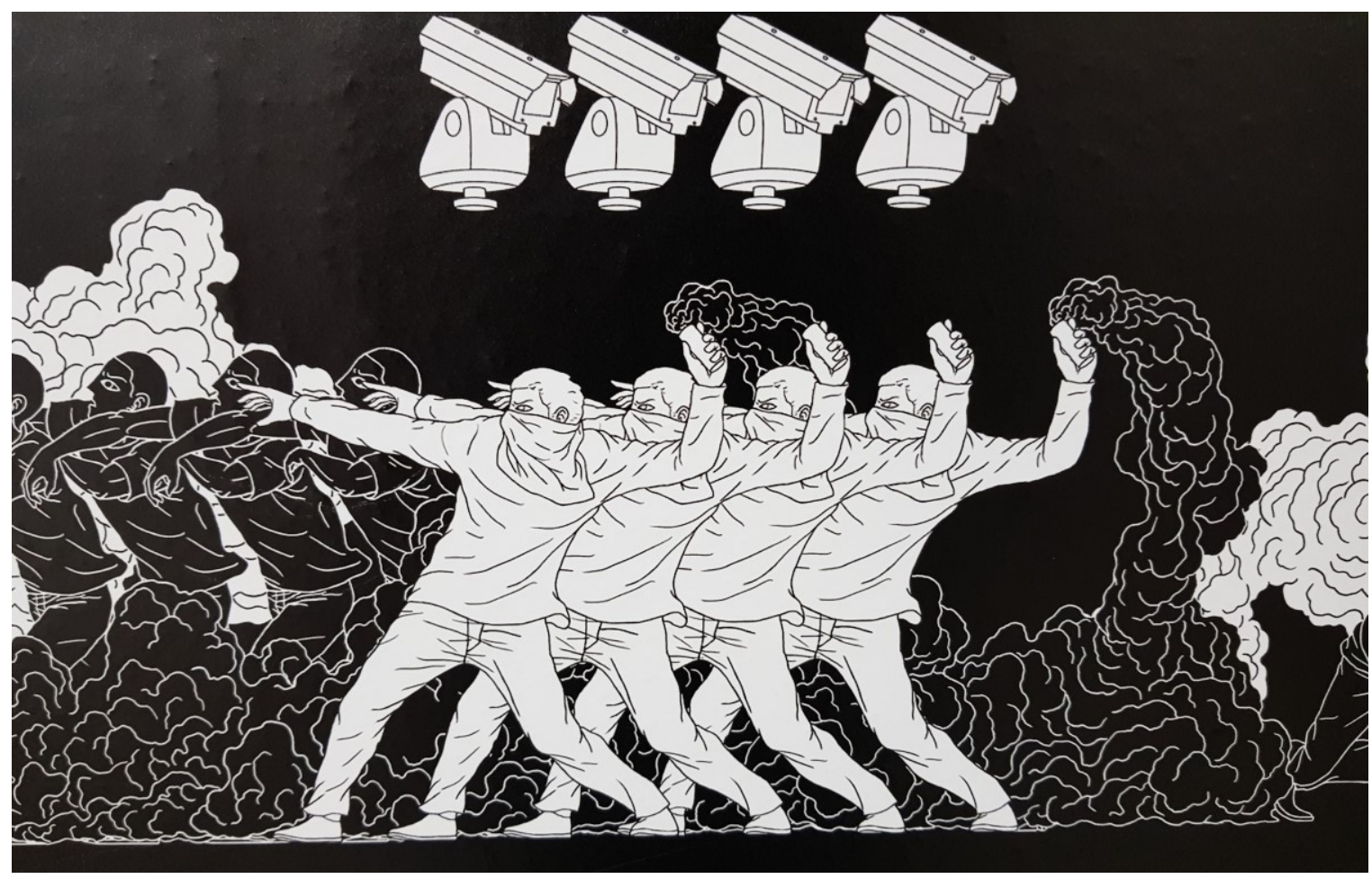

Figura 5 - Ai Weiwei, Odisseia (detalhes), 2017. Vinil adesivo. Oca, São Paulo Fonte: Arquivo da autora.

$\mathrm{Na}$ exposição de Didi-Huberman, ele inventariou imagens de diversos tempos e em diversas mídias de corpos em sublevação, cristalizados em imagens de braços levantados, rostos crispados em discursos inflamados, mãos às armas ou estandartes, corpos prontos para a luta. O historiador da arte afirma que "[...] o levante é um gesto sem fim, incessantemente retomado, soberano como pode ser chamado soberano o próprio desejo ou essa pulsão, esse 'impulso de liberdade' (Freiheitsdrang) de que falou Sigmund Freud" (2017, p. 17). E reflete sobre essa fórmula de páthos: levantar-se é "erguer os braços ao futuro que se abre. É um sinal de esperança e resistência. É um gesto e uma emoção" (DIDI-HUBERMAN, 2017, p. 117).

Esses "gestos emotivos imemoriais" (DIDI-HUBERMAN, 2016, p. 35) apresentam-se na morte do herói (Figura 6), motivo antigo que remonta às imagens da morte de Aquiles ou Meleagro, frequente em sarcófagos antigos e, depois, absorvido na iconografia cristã no motivo do sepultamento de Cristo. Esse tema é explorado por Warburg na prancha 42 do Atlas Mnemosyne (2012). 


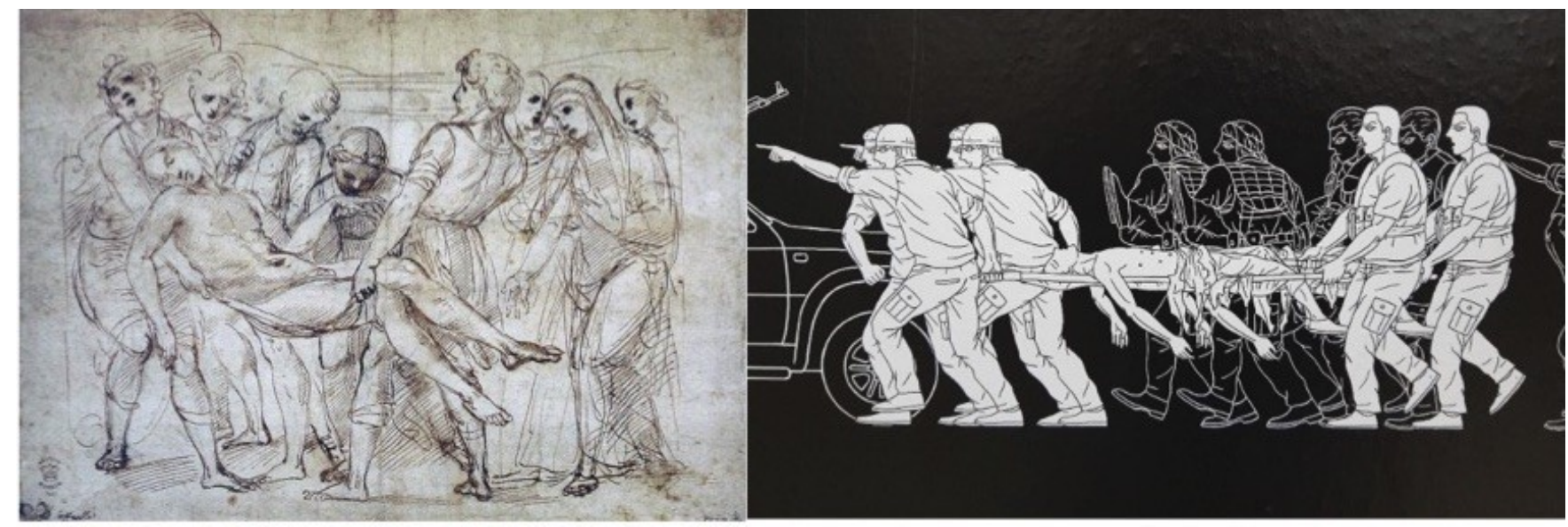

Figura 6 - À esq. Rafael Sanzio, O sepultamento, c. 1506. Nanquim marrom sobre papel e giz preto, 22.8 X31.8 cm, British Museum. Fonte: https://www.britishmuseum.org/collection/object/P_1855-0214-1

À dir. Ai Weiwei, Odisseia (detalhe), 2017. Vinil adesivo. Oca, São Paulo. Fonte: Arquivo da autora.

E tal motivo desdobra-se em outra fórmula bem familiar ao espectador ocidental, a deposição do corpo de Cristo e a desolação, o luto da Mãe. Reconhecemos a Pietá, de Michelângelo, em roupagem refugiada: a mãe enlutada acolhe o corpo baleado do filho nos braços em meio a edifícios arruinados por bombas e escombros de edificações gregas e a cabeça de uma estátua coroada (Figura 7).

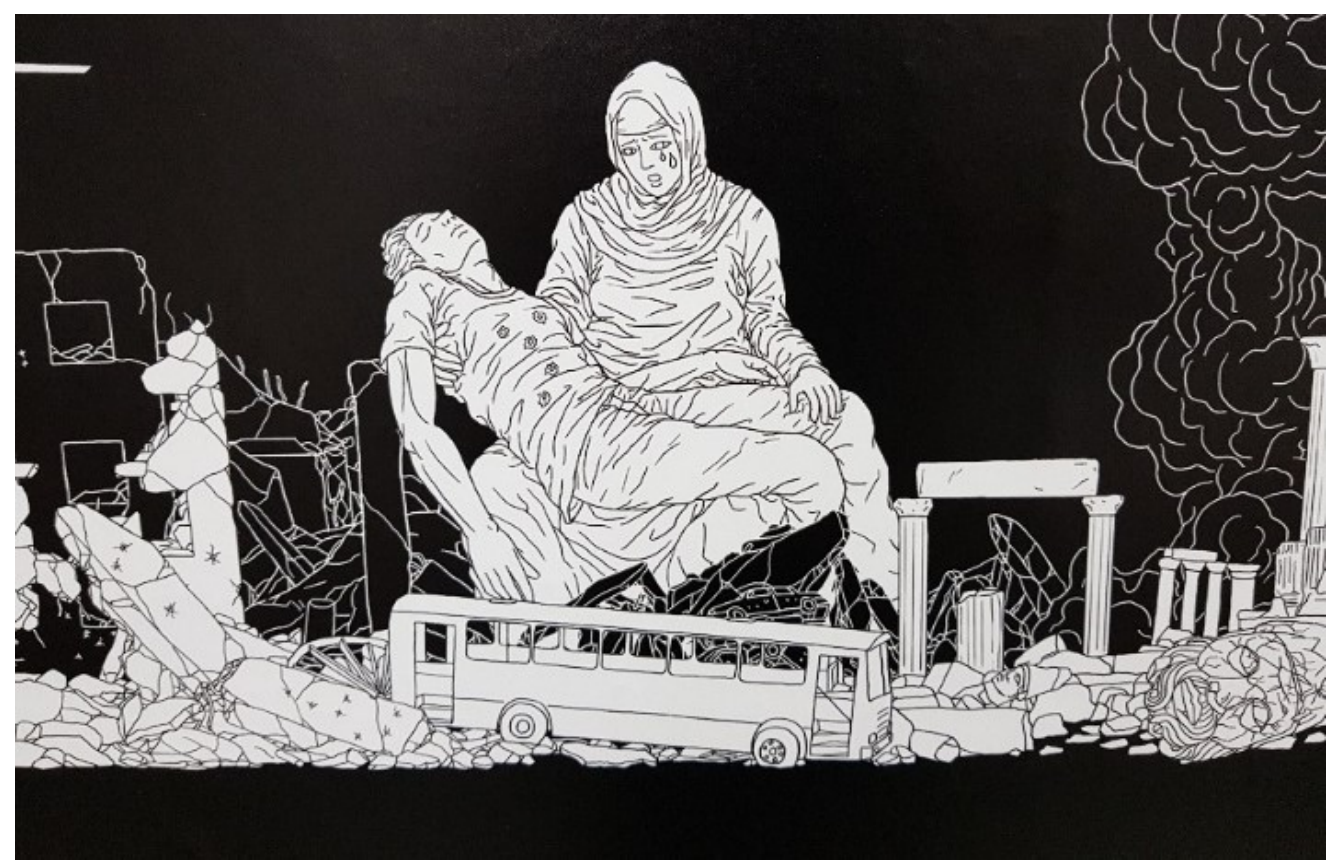

Figura 7 - Ai Weiwei, Odisseia (detalhe), 2017. Vinil adesivo. Oca, São Paulo Fonte: Arquivo da autora.

$\mathrm{Na}$ desoladora jornada dos refugiados, encontramos a ninfa canéfora e o gesto da proteção e guia da criança. Esses motivos aparecem nas pranchas 46 e 47, respectivamente, do Atlas Mnemosyne, de Warburg (Figura 8). 

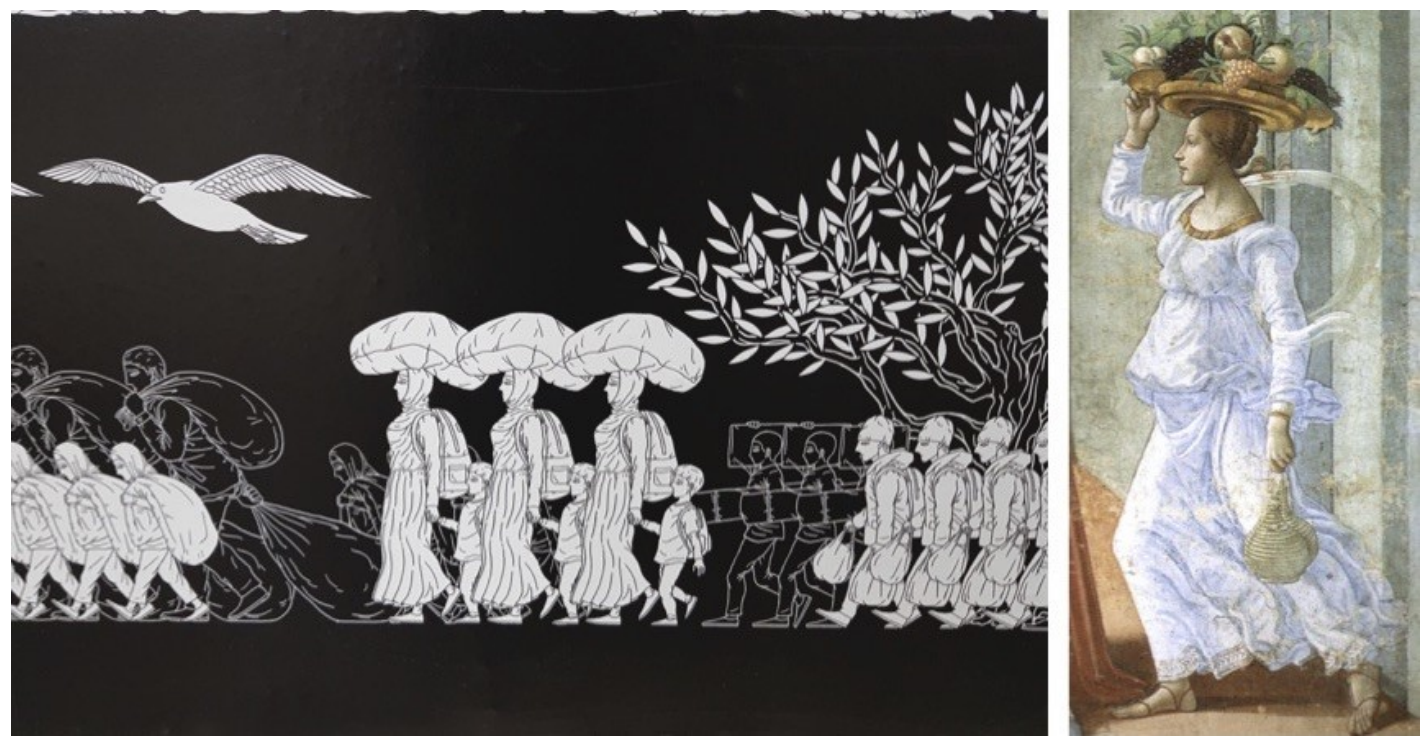

Figura 8 - À esq. Ai Weiwei, Odisseia (detalhe), 2017. Vinil adesivo. Oca, São Paulo. Fonte: Arquivo da autora. À dir. Domenico Ghirlandaio, O nascimento de São João Batista (detalhe), 1486-1490, Afresco, Santa Maria Novella, Florença. Fonte: http://warburg.chaa-unicamp.com.br/obras/view/10922

Sintomática da união entre passado e presente, é a imagem apresentada por Ai Weiwei, no painel "Odisseia", do menino sírio Aylan Kurdi, de três anos, morto na praia de Lesbos, na Turquia, o qual virou símbolo da crise migratória que já matou milhares de pessoas do Oriente Médio e da África que tentam chegar à Europa para escapar de guerras, de perseguições e da pobreza. A criança era um dos doze refugiados sírios que morreram afogados, tentando chegar à ilha grega em 2015 (Figura 6). Não apenas inseriu a imagem no painel, como, em 2016, o artista deitou-se na mesma praia, com uma pose que nos recorda as imagens captadas em setembro de 2015, altura em que o corpo do menino deu à costa na cidade costeira turca de Bodrum (Figura 9). 

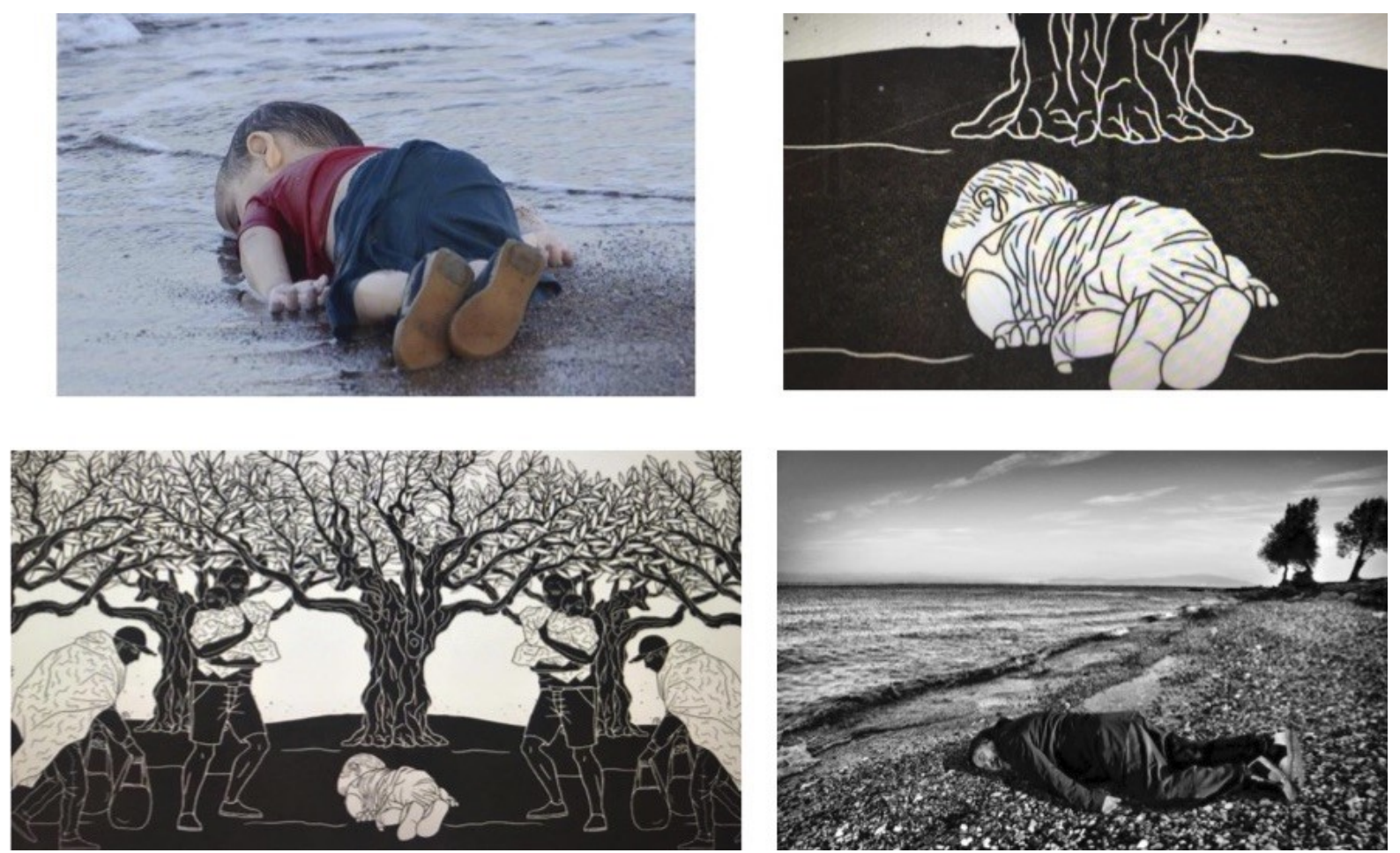

Figura 9 - Aylan Kuri, 3, morto por afogamento na praia de Lesbos, Turquia. Fonte: (Nilufer Demir/DOGAN NEWS AGENCY/AFP). Cenas do painel de Odisseia. Fonte: Arquivo das autoras. Por último, em fotografia publicada pela revista India Today, o artista e ativista Ai Weiwei recriou imagem do menino Aylan Kurdi. Foto: Rohit Chawla/India Today via AP, 2016. Fonte: Arquivo das autoras.

\section{Como e por que essas formas/fórmulas antigas retornam em Ai Weiwei?}

Ai Weiwei já é um clássico de nosso tempo, pois sua obra é como se escapasse à lei inexorável do devir do tempo, esbanjando invejável permanência no mundo por onde tudo passa. A obra possui vigor de presente que, para os clássicos, explicava-se por ela ser a encarnação de certo modelo atemporal. As obras de Ai Weiwei são tão essencialmente históricas que trazem a história dentro de si. Toda obra, ao se escrever, escreve também sua história. "É preciso que a obra crie ela própria a sua posteridade" (PROUST,1988, p. 97). A arte não é apenas fruto de seu contexto histórico. Ela também cria o seu contexto particular e, assim, inventa sua própria história. Ela é capaz, por isso, de comunicação com o presente, mesmo que seu passado datado esteja separado pela cronologia que lhe é exterior por milênios de distância, como é o caso da epopeia grega em relação aos tempos modernos. Se os clássicos são referências, não o são para que os copiemos, mas para que, ao imitálos, imitemos inclusive o fato de que eles, ao criarem, não imitaram ninguém. Era esta já a lição de J. Winckelmann no século XVIII alemão: "o único meio de nos tornarmos grandes e, se possível, inimitáveis é imitar os antigos" (WINCKELMANN, 1990, p. 94-95). Ai Weiwei estabelece novo relacionamento com o passado a partir da própria busca pelo novo. Esta se perpetua dentro da história, não fora dela. No contato com os clássicos, experimentamos, então, o acontecimento de sua verdade que, por ser não apenas fruto do tempo, mas também agente do tempo, jamais cessa de acontecer: ontem, hoje e amanhã. Os clássicos são textos que serão sempre retomados no sentido de debater sobre a condição da humanidade, a busca do homem pelo conhecimento de si e das relações humanas. Entendemos que é por isto que fórmulas antigas retornam em Ai Weiwei.

George Steiner (2006) fornece-nos mais pistas para entender a postura do artista. Na tese do autor no livro Tolstói ou Dostoiévski, há dois tipos de alma: ou você está próximo de Dostoiévski (18211881) ou de Tolstói (1828-1910). O ambiente (rural em Tolstói e citadino em Dostoiévski), a teologia (discordâncias entre o conceito de moral e de Terra Prometida), personagens (a totalidade 
de objetos em Tolstói ou o estritamente dispensável em Dostoiévski), a filosofia (a metáfora do governo de Deus em Tolstói ou a independência e imprevisibilidade do homem em Dostoiévski) são objetos de análise aprofundada. São opostos, mas não remotos nem estranhos. E nos servem para situarmos o ativismo de Ai Weiwei, que é pensado à luz das categorias de épico e trágico, como descritas por George Steiner acerca de Tolstói e Dostoiévski.

Steiner defende também que a beleza e o amor suspendem a vida acima da banalidade do cotidiano. Despertá-los, talvez, seja a missão mais sublime que alguém pode ter na vida com relação aos seus semelhantes. A tipologia que nos propõe Steiner baseia-se nas raízes nos dois estilos gregos: o épico e o trágico. Tolstói estaria no primeiro, Dostoiévski no segundo. E, por consequência, são dois modos distintos de viver a vida, e ambos carregam a grandiosidade de espíritos avassaladores, como os dois escritores russos. "Não há, entre os dois, disparidades de estatura: eram ambos titãs." (STEINER, 2006, p. 7).

O épico seria o estilo em que a vida está envolvida pela presença do mito ou da religião, fundando uma ação fincada na esperança prática do transcendente (mundo dos deuses) e, por consequência, na esperança da redenção do mundo. Salvar o mundo é sua marca. Pessoas épicas sentiriam que suas vidas são acompanhadas por forças que as tornam capazes de redimir o mundo de suas misérias. Sua virtude central é a esperança. Almas tolstoianas lutam a cada dia contra a miséria do mundo, fazendo dele um campo de batalha contra o mal, movidas por uma certeza que parece alucinada.

O trágico seria o estilo em que o olhar para a vida mantém-se fincado na fragilidade dela. A precariedade é a estrutura dinâmica da vida. Aqui não há redenção, há coragem de enfrentar esse "desastre" que é a existência humana. Para Steiner, essa é a alma dostoievskiana. Sua virtude central é a coragem. Almas dostoievskianas um tanto mais delicadas suportam o sofrimento, encantando o mundo à sua volta com piedade e sinceridade avassaladoras.

Reconhecemos em Ai Weiwei uma alma trágica, cuja virtude central é a coragem. Acerca de uma exposição do tema dos refugiados no Qatar em 2018, o artista afirmou em entrevista: "Em vez de ser exclusivista, míope e covarde, cada estado precisa arcar com a responsabilidade. Não podemos rejeitar a ideia de que a humanidade é uma só" ${ }^{10}$. As virtudes em Liev Tolstói são a esperança e a força, em um estilo épico. Em Fiódor Dostoiévski, destacam-se a coragem e a piedade, em um estilo trágico. Lamenta-se que pensar em Dostoiévski e Tolstói pressupõe reflexão e metafísica, para se tornarem reais no cotidiano. E convenhamos, são duas coisas totalmente em falta na atual sociedade.

\section{Considerações finais}

Estamos a dizer que Ai Weiwei é um clássico que atualiza os clássicos. O que o torna original é a capacidade de reinventar a tradição, atualizando o enfoque de acordo com os problemas de sua época e a atualiza de acordo com a urgência dos problemas atuais. A obra clássica potencializa formativamente o conflito entre a tradição e o momento atual, permitindo sonhar com o que está por vir. Melhor, talvez do que outra produção cultural humana, a obra clássica permite compreender a interminável balança entre passado, presente e futuro. Tal balança, que oscila o tempo todo, constitui o Self humano, ou seja, a própria identidade humana, uma vez que ela é parte da cultura herdada e daquela em que o ser humano se encontra, ajudando-o a construir a noção do momento histórico em que vive.

10 Artista e ativista, Ai Weiwei expõe no Qatar instalação sobre refugiados. 28/05/2018. Disponível em: https://www1.folha.uol.com.br/ilustrada/2018/05/artista-e-ativista-ai-weiwei-expoe-no-qatar-instalacao-sobrerefugiados.shtml Acesso em: 02 nov.2020. 
A obra é clássica, porque possui o imenso poder de mexer com o leitor, deixando-o muito diferente do que era antes de iniciar a leitura. Por ser clássica, possui força transformadora para melhor, na medida em que confronta o leitor com suas limitações. Conhecer e enfrentar suas próprias limitações na amizade reveladora de grandes companhias é uma dimensão do sofrimento humano, profundamente formativa e, por isso, muito exigente, bem aos termos do pathos formativo da tragédia grega.

Concordando com Duarte (2018) na contramão das novidades rasteiras de nosso mundo, que chegam com a mesma velocidade que vão, e reafirmando que o ativismo de Ai Weiwei diferenciase de muitos dos empobrecidos ativismos da agenda contemporânea, os clássicos são a paradoxal existência da novidade que não se esvai. Se hoje em dia abundam as novas obras que já nascem velhas, os clássicos são, pelo contrário, as velhas obras nas quais o novo não cessa de nascer. Ai Weiwei demonstra-nos isso em sua obra Odisseia.

\section{Referências:}

AGAMBEN, G. O que resta de Auschwitz: o arquivo e a testemunha. São Paulo: Boitempo, 2008.

AI WEIWEI: AT SEA. Disponível em https://vimeo.com/470501346. Acesso em: 22 out. 2020. Vídeo.

DANTAS, M. (org.). Raiz Weiwei. São Paulo: Ubu Editora, 2018.

DIDI-HUBERMAN, G. Que emoção! Que emoção? São Paulo: Editora 34, 2016.

DIDI-HUBERMAN, G. (org.). Levantes. São Paulo: Edições Sesc São Paulo, 2017.

DIDI-HUBERMAN, G. Imagens apesar de tudo. São Paulo: Editora 34, 2020.

DUARTE, P. O que faz de uma obra um clássico? Revista Poiésis, Niterói, n. 11, p.191-196, nov. 2008.

HOMERO. Odisseia. Rio de Janeiro: Nova Fronteira, 2011.

HURTTIG, M. A. Introduction. In: HURTTIG, Marcus Andrew (org.). Antiquity Unleashed: Aby Warburg, Dürer and Mantegna. London: The Courtauld Gallery, 2013. p. 13-22.

MULLER, S. Deslocamentos humanos: a Odisseia de Ai Weiwei. Ide (São Paulo), São Paulo, v. 40, n. 66, p. 71-74, dez. 2018. Disponível em:

http://pepsic.bvsalud.org/scielo.php?script=sci_arttext\&pid=S0101-

$31062018000200007 \& \operatorname{lng}=$ pt\&nrm=iso. Acesso em: 25 out. 2020.

OBRIST, H. U. Prefácio. In: WEIWEI, A. Ai Weiwei: Entrevistado por Hans Ulrich Obrist. Rio de Janeiro: Cobogó, 2018. p. 11-14.

ODYSSEY. Disponível em: https://vimeo.com/470932544. Acesso em: 22 out.2020. Vídeo.

ODYSSEY: Ai Weiwei a Palermo - ZAC Cantieri Culturali della Zisa (Slide show). Disponível em: https://www.youtube.com/watch?v=ah1rxUFENd4. Acesso em: 22 out. 2020. Vídeo.

PROUST, M. À sombra das raparigas em flor. Rio de Janeiro: Editora Globo, 1988.

STEINER, G. Tolstói ou Dostoiévski: um ensaio sobre o velho criticismo. São Paulo: Perspectiva, 2006.

SOCIAL SCULPTURE. Art Term: Tate. Disponível em: https://www.tate.org.uk/art/artterms/s/social-sculpture Acesso em: 02 nov. 2020.

WARBURG, A. Dürer e a Antiguidade italiana (1905). In: WARBURG, A. A Renovação da Antiguidade Pagã. Rio de Janeiro: Contraponto, 2013. p. 435-445. 
WARBURG, A. Mnemosyne. O Atlas das imagens. Introdução. In: WARBURG, A. A presença do antigo. Campinas: UNICAMP, 2018. p. 217-229.

WEIWEI, A. Ai Weiwei: Entrevistado por Hans Ulrich Obrist. Rio de Janeiro: Cobogó, 2018.

WINCKELMANN, J. J. Réflexions sur l'imitation des oeuvres grecques en pinture et en sculpture. Paris: Aubier, 1990. 